\title{
Inexpensive apparatuses for use with young children: A WGTA variant
}

\author{
MICHAEL WYRICK and KATHRYN B. SHERROD \\ John F. Kennedy Center for Research on Education and Human Development \\ George Peabody College for Teachers, Nashville, Tennessee 37203
}

\begin{abstract}
This report details steps for constructing devices adapted from the WGTA and for use with young children in discrimination tasks. The devices are specially made Jack-in-the-boxes to which various discrimination forms can be attached. The units are both durable and reliable and meet the criteria of ease of construction, low cost, ease of operation, and strong reinforcing qualities. The units have been successfully used with normal and retarded children and with children with motor difficulties and/or muscle weaknesses from 15 to 60 months of age.
\end{abstract}

This report describes steps for constructing a WGTA variant that has been used successfully in learning-set studies with young mentally retarded and nonretarded children (Wyrick \& Sherrod, Note 1; Wyrick, Sherrod, $\&$ Borrebach, Note 2). The manipulanda (specially made Jack-in-the-boxes) were constructed because commercially available boxes could not be successfully adapted for research. The units are rugged and reliable and not subject to spurious activation due to hard glancing blows by children. The apparatus meets four design criteria: (1) ease of construction, (2) low cost, (3) ease of manipulation for children with motor difficulties, and (4) strong positive reinforcing qualities.

\section{APPARATUS}

The apparatus units are specially constructed Jackin-the-boxes in the form of $14-\mathrm{cm}$ cubes made from black Plexiglas. The base of each box is $16 \mathrm{~cm}$ wide in order to fit into special mounting tracks. The puppets with attached springs are from commercial crankoperated Jack-in-the-boxes made by Mattel; Fisher-Price puppets are equally suitable. The units can be purchased for about $\$ 6$ each. The puppet and spring are mounted inside a plastic cylinder in the center of the Plexiglas Jack-in-the-box.

The boxes have push-type triggering mechanisms extending $5 \mathrm{~cm}$ from each box to which the various Plexiglas forms can be attached; thus, during testing, the boxes need never be touched by the child. Pushing the Plexiglas form mounted on the triggering device releases the catch holding the lid closed and allows

Development of this apparatus and the preparation of this report was supported by NICHD Grant 00973. Drawings were made by Mary Lou Ashe and photographs were made by Daniel I. Drake, both of the John F. Kennedy Center for Research on Education and Human Development. Send reprint requests to M. W., IMRID, Box 154, Peabody College, Nashville, Tennessee 37203. the puppet to spring up. Individual boxes can be locked so that no amount of manipulation of the form can activate the puppet. The lock is operated by a knurled knob screwed into the outside front of the box, with the shaft located directly above the triggering mechanism. When the knob is screwed in, the shaft of the screw prevents movement of the triggering mechanism.

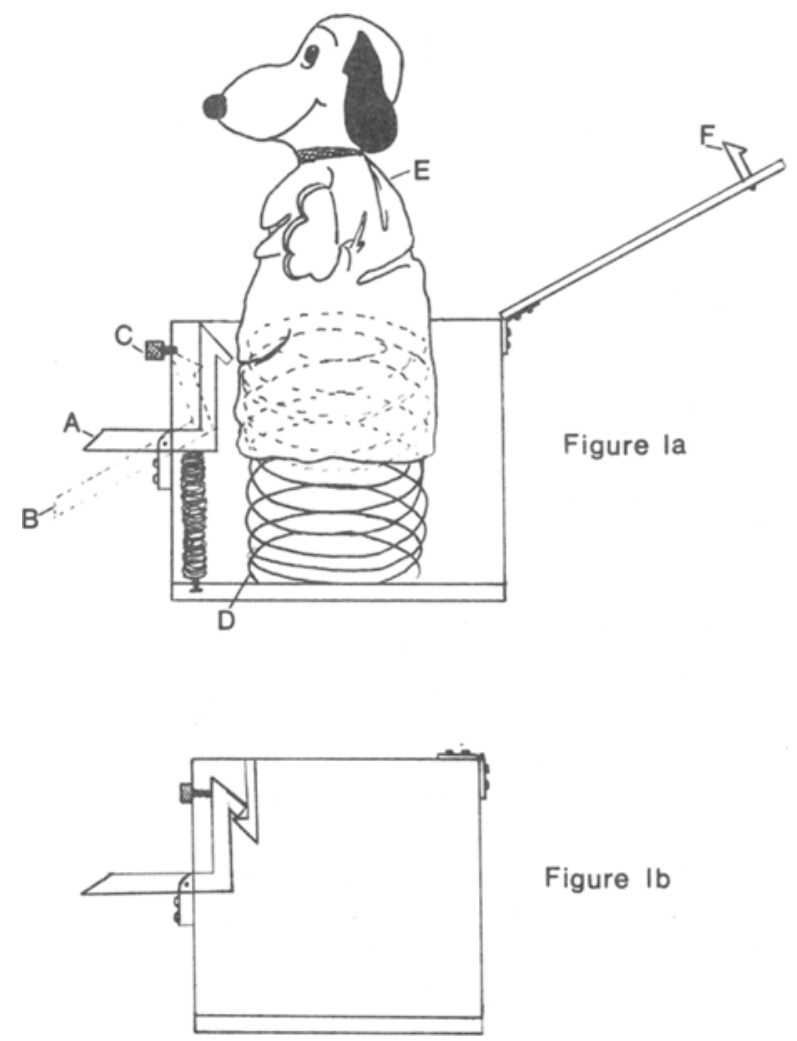

Figure la. Cut-away side view showing trigger and latch mechanism (A), trigger and latch movement (B), lock knob in open position (C), cylinder and spring (D), puppet (E), and lid latch (F). Figure 1b. Cut-away showing lid closed and locked. 


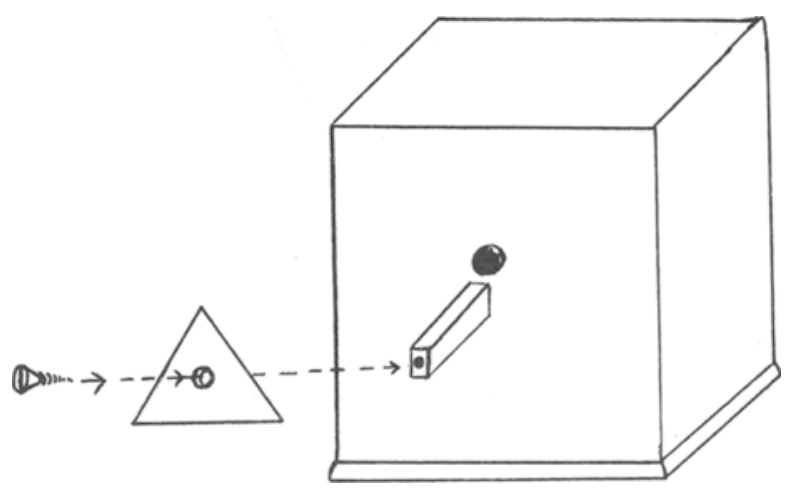

Figure 2. Front view showing placement and attachment of form to trigger.

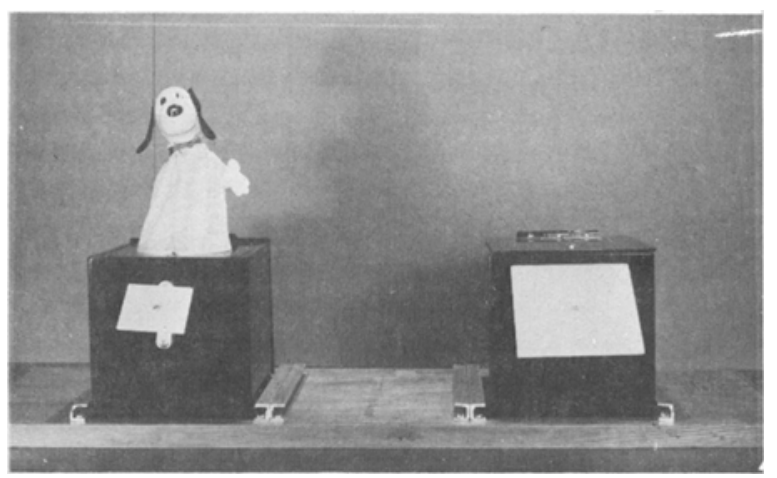

Figure 3. Two-choice discrimination setting showing vacant center tracks.

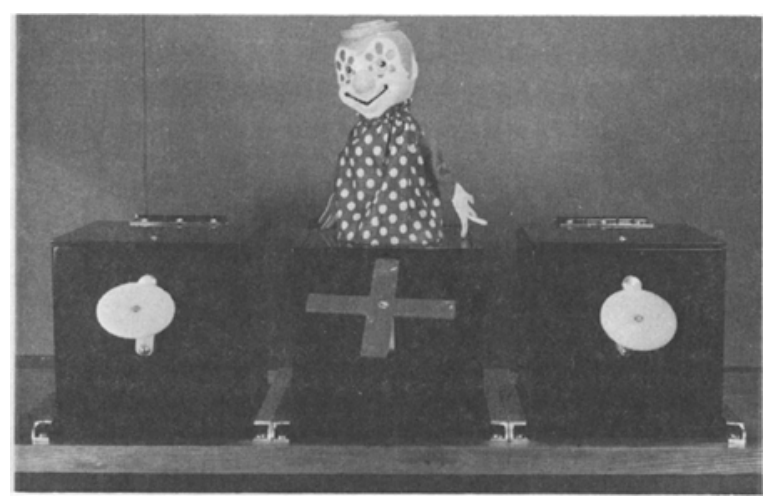

Figure 4. Oddity discrimination setting.

When the knob is retracted, the triggering mechanism is functional and can be depressed to release the lid catch. The knob position cannot be seen by the subject when a discrimination form is in place (see Figure 1).
Discrimination forms can be of any variety. The forms used in our studies are made from 3-mm-thick Plexiglas and vary in size (large stimuli were $12 \mathrm{~cm}$ at the longest dimension, small sizes were $6 \mathrm{~cm}$ at the longest dimension), shape (circle, square, cross, and triangle), and color (red, yellow, blue, and green). A hole in the center of each form allows it to be fastened to the front of the triggering device with a small set screw. These forms are easily removed and replaced during testing (see Figure 2).

During testing, the Jack-in-the-boxes are fitted onto a $30 \times 60 \times 2 \mathrm{~cm}$ tracked board. The tracks are three adjoining pairs of slotted aluminum rails mounted on the board, each pair having a $16-\mathrm{cm}$ separation. The base of a Jack-in-the-box may be positioned into any pair of rails. A permanently mounted stop screw at one end of the tracks prevents the boxes from being pulled out by the child; they can be put on or removed only from the experimenter's side of the board. Since the tracks allow for three positions on the board, either object-quality (Figure 3 ) or oddity trials (Figure 4) can be administered. During object-quality testing, the boxes on any given trial can be either 3 or $20 \mathrm{~cm}$ apart. The boxes can be easily removed and repositioned during a testing session, just as with other WGTA adaptations.

Construction is not time consuming; four Jack-inthe-boxes and tracked board plus the forms were built for less than $\$ 150$. The reinforcing qualities of form manipulation and subsequent puppet appearance are readily apparent with both retarded and nonretarded children. This apparatus has been successfully used with children 15 to 60 months of age, as well as with children with problems of motor cuntrol and/or muscle weaknesses.

\section{REFERENCE NOTES}

1. Wyrick, M. E., \& Sherrod, K. B. Oddity discriminations of stimuli with uni- and multidimensional differrences in young mentally retarded children. Manuscript in preparation.

2. Wyrick, M. E., Sherrod, K. B., \& Borrebach, D. E. Learning-set formation in retarded and nonretarded nursery school children. Manuscript in preparation.

(Accepted for publication February 15, 1978.) 